\title{
Teachers' Mole Concept Pedagogical Content Knowledge: Developing the Model for the mole Concept Content Representations Framework
}

\author{
Emmanuel Mweshi $^{1^{*}} \quad$ Onesmus Munyati $^{2} \quad$ Kabuga Nachiyunde. ${ }^{3}$ \\ 1.Mukuba University, School of Education, P.O Box 20382, Kitwe, Zambia \\ 2.The University of Zambia, School of Natural Sciences, Box 23279, Lusaka, Zambia \\ 3.The University of Zambia, School of Education, Box 23279, Lusaka, Zambia
}

\begin{abstract}
Teaching and learning difficulties have been documented in numerous studies in literature. However not much has been done to develop a model of the mole concept Content Representations (CoRes) framework to simultaneously enhance teachers' mole concept Content Knowledge (CK) and Pedagogical Content Knowledge (PCK). Thus the study sought to fill up this gap in literature by developing the model of the mole concept CoRes framework through the assessment of teachers' mole concept PCK. The study was conducted in 6 selected secondary schools in Kitwe district in the Copperbelt province of Zambia with a study sample of 30 grade 11 chemistry teachers. The data was collected using the questionnaire, lesson observations, Content Representations (CoRes) framework, and focus group discussion. The data was analysed by categorising it into themes captured by the conceptual framework of the study. The findings of the study revealed that teachers' mole concept PCK was weak and this was largely attributed to their conceptual limitations exhibited in their mole concept CK. Their presentation of the topic was characterised by algorithmic approaches, semantics mistakes and didactic difficulties. The developed mole concept CoRes framework focuses on addressing the conceptual and didactic limitations identified in literature and by the study.
\end{abstract}

Keywords: Mole concept, content knowledge, Pedagogical Content Knowledge

DOI: $10.7176 / \mathrm{JEP} / 10-8-08$

Publication date:March $31^{\text {st }} 2019$

\section{Introduction}

The mole concept is defined as the amount of substance of a system which contains as many elementary entities (atoms, molecules, ions, electrons, quanta, or other entities) as there are carbon atoms in $0.012 \mathrm{~kg}$ of C-12 isotope (Fang, Hart \& Clark, 2014; Furio et al., 2000). The concept makes it possible to count the microscopic entities taking part in chemical processes by carrying out chemical reactions at macroscopic level using volumes and masses of reacting substances (Furio et al., 2000; Furio, Azcon \& Guisasola, 2002). Thus an understanding of the mole concept is key in laying a strong foundation in chemistry. However, research findings in various studies globally indicate that teachers find it difficult to teach the concept (Furio et al., 2000). This implies that teachers don't have adequate knowledge to transform the mole concept CK in the form that could be easily be understood by learners. Shulman $(1986,1987)$ identified this knowledge as PCK. He described PCK as "the capacity of a teacher to transform the content knowledge he or she possesses into forms that are pedagogically powerful and yet adaptive to the variations in ability and background presented by the learners" $(1987 ; 15)$.

\subsection{Background of the study}

The mole concept is one of the fundamental topics covered in chemistry 5070 and science 5124 syllabi in the Zambian Ordinary Level science curriculum. Chemistry 5070 is pure chemistry while science 5124 is a combination of chemistry and physics. The scope of the coverage of the mole concept outlined by the two syllabi is the same. The understanding of the mole concept is crucial in laying learners' strong foundation in chemistry and consequently their performance at grade 12 and advanced levels. Nonetheless, the Examination Council of Zambia (ECZ) reports from 2006 to 2014 revealed that poor understanding of the mole concept by learners has been one of the major contributing factors to the poor performance in chemistry at 12 examination level. The overall average pass percentage for the 10 typical secondary schools in Zambia from 2006 to 2014 was $33 \%$ and $23 \%$ in chemistry (5070) and science (5124) respectively. The reports further explained that the reason why learners performed poorly was that the mole concept seemed to be a challenging topic for teachers. The reports resonate with results of many studies in literature which shows that teachers and learners face a lot of difficulties in the teaching and learning of the mole concept (Furio et al., 2000) Learning difficulties and consequently their poor performance in mole concept can be to larger extent attributed to the teachers' difficulties in presenting the concept. Thus there was a need to assess the chemistry teachers' mole concept PCK. 


\subsection{Statement of the Problem}

There has been a consensus among the findings of various studies that teachers lack the scientific conception of the mole concept and consequently face a lot of difficulties in teaching the topic (Furio et al., 2000; Padilla \& Furio 2007; Fang, Hart \& Clarke., 2014; Malcolm, Mavhunga \& Rollnick, 2018). Despite these findings, not much has been done in coming up with a model of a mole concept Content Representations (CoRes) framework to guide and enhance teachers' mole concept PCK and consequently improve the learners' understanding of the concept.

\subsection{Purpose of the study}

The study sought to develop a model for mole concept CoRes framework through the assessment of teachers' mole concept PCK

\subsection{Objectives of the study}

The study objectives were to:

i. $\quad$ Assess the teachers' mole concept Pedagogical Content Knowledge

ii. Develop a Content Representations framework for conceptual understanding and effective teaching of the mole concept.

\section{Literature Review}

The findings of numerous studies on the teaching and learning of the mole concept present a gloomy picture of how the mole concept is presented within the education domain. The findings show that there are various descriptions of the mole concept within the education domain which are inconsistent with the meaning of SI definition of the mole concept as conceptualised within the scientific domain. Teachers and learners face a lot of teaching and learning difficulties of the topic respectively (Furio et al, 2000; Malcolm, Mavhunga \& Rollnick, 2018; Padilla \& Furio, 2007;). On the other hand, Fang, Hart and Clarke (2014) observed that although it is necessary that teachers and students' conception of the mole should be consistent with the SI definition, this does not imply that the SI definition is the most effective and appropriate instructional presentation of the mole concept. Other scholars have echoed this observation that it is very difficult to teach the mole concept in the form it was constructed by the scientists, especially on the meaning of the 'amount of substance'. There is still a controversy over the meaning of the term 'amount of substance even among scholars and this may be the source of the inconsistencies reported in the literature (Furio, Azcona \& Guisasola, 2002; Padilla \& Furio 2007). It is not surprising that authors and teachers try various strategies and representations to unpack the meaning of the SI definition just to make the concept comprehensible to learners. It is against this backdrop that there are so many descriptions of the mole within the education domain.

There has been a shift in research from focusing only on teaching and learning difficulties to the understanding of the knowledge possessed by teachers in the transformation of the mole concept CK. In their study, Rollnick et al. (2008) sought to determine the quality of teachers' mole concept PCK, they found out that although teachers demonstrated to have some classroom experience and showed a good understanding of their learners' context as well as the ability to develop teaching procedures, their mole concept PCK was weak. Teachers' knowledge of; what makes the concept difficult to understand, learners' prior knowledge, representations and conceptual strategies was inadequate (Rollnick et al., 2008). This was attributed to their inadequate understanding of the multiple meanings of the associations embedded in the conceptual network of the mole concepts. In another study, Padilla et al (2008) sought to derive the Content Representations (CoRes) of the undergraduate college professors. They examined their content representation using the five zones of Mortimer's (1995) Conceptual Profile Model (CPM) to evaluate the way in which participants structured their knowledge of the topic 'amount of substance. The findings revealed that the participants' CoRes were weak because they lacked the accepted model for the conceptual understanding of the amount of substance. Only one professor out of four exhibited the accepted CPM, the formal rationalist conceptual profile zone, zone is located within the atomistic paradigm. The zone holds the view that the amount of substance is a conceptual network that involves macroscopic measurement of a mass or volume, and at the same time counting of defined microscopic elementary entities.

In the more current study, Malcolm, Mavhunga \& Rollnick (2018) sought to develop a lesson on teaching the mole conceptually using the Topic Specific Pedagogical Content Knowledge model developed by Mavhunga and Rollnick (2013). They used the CoRes framework to identify key aspects of student understanding of the multiple meanings in the conceptual network embedded in the SI definition of the mole concept. They used the generated knowledge to develop a series of lessons in the form of lesson study cycle of action research to come up with a lesson that made a clear distinction between the amount of substance, mass, the volume of gases and number of particles. The lesson used conceptual strategies that integrated macro, micro and symbolic representation of the mole concept. Surprisingly, they found that there was no significant improvement in the learners understanding of the concept after the lessons. The gap identified in the lessons was that there was no attempt to make learners to understand relative atomic mass as linking idea of the atomic theory and the mole concept. It has been argued by 
Fang, Hart and Clark $(2014,2016)$ that even if the mole concept is taught conceptually learners will still to struggle to understand the concept unless the meaningful link is made between relative atomic/molecular and molar mass is made. The developed mole CoRes framework in this study has addressed this gap in the teaching and learning of the mole concept.

The focus of the above-cited studies on mole concept PCK, except the study by Malcom, Mavhunga and Rollnick (2018), has been to judge as opposed to understand and to develop the CoRes framework that would enhance teachers PCK. The emphasis has been to develop and use instruments that will make PCK explicit and measure it in a valid manner. These methodological approaches overlook the complexity of PCK. Teachers' PCK is a personal professional knowledge base. Thus it can be can be sensitive to personal characteristics and working environment (Van Driel \& Berry, 2010; Guess-Newsome, 1999; Loughran et al, 2001, 2004) This study, therefore, focused on understanding how teachers understood and presented the underlying ideas and concepts under the mole concept topic within their normal teaching environment as a way of accessing their PCK. This approach was critical in the development of the model of CoRes framework for conceptual understanding and effective teaching of the mole concept.

\subsection{Conceptual Framework}

The conceptual framework captured the key concepts and ideas and their relationships in this study. The framework integrated the modified TSPCK model and the mole concept CK. The TSPCK was informed by the model developed by Mavhunga and Rollnick (2013). The mole concept CK constituted concepts and ideas captured in the modified concept map by Fang, Hart and Clarke, (2014) for conceptual understanding of the mole concept.

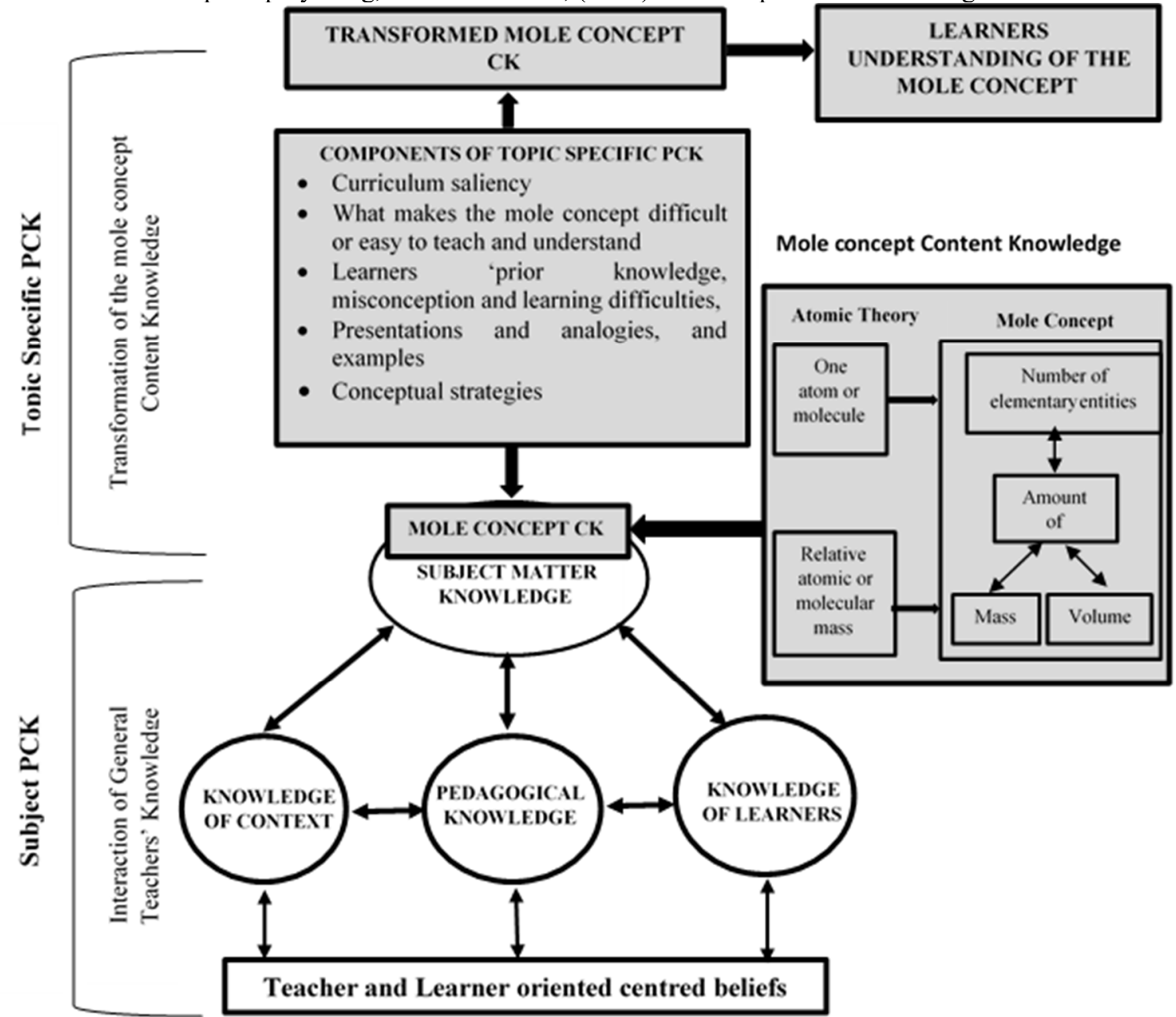

Fig 1. The conceptual framework for mole concept PCK

The conceptual framework supports the view that PCK is very much located within the topic and that CK is the precursor for the development of knowledge components of TSPCK (Gess-Newsome, 2015; Kind, 2009, Mavhunga \& Rollnick, 2013).

The PCK has been discussed using different models the main ones being; transformative, integrative and PCK models from the psychological perspective (Loughran et al, 2001, 2004; Kind, 2009). The transformative model holds the view that CK is not part of PCK. It proposes that the teacher transforms CK using the knowledge 
components of TSPCK into the form that is comprehensible to learners. While the integrative models view PCK as the integration of CK, PCK and Context. Thus CK is seen as part of PCK. The models from the constructivist view consider PCK as a continuous understanding by teachers that create teaching strategies for teaching specific content in a discipline in ways that enable learners to construct useful understandings in a given context (Kind 2009). Despite having different views on PCK, all these models agree that PCK is topic specific, developed through experience, and CK is essential for the development of PCK. The study adopted the transformative model because it offers a mechanism to explain how the transformation of CK happens at topic level (Grossman, 1990; Magnusson et al, 1999: Kind, 2009; Mavhunga \& Rollnick, 2013).

The conceptual framework captured what constitutes mole concept CK and how it is transformed through the components of TSPCK by the teacher in a classroom practice to make the mole concept comprehensible to learners. When teaching a topic, a teacher thinks about a topic through content specific components of PCK through which he or she generates understanding for teaching that topic (Mavhunga \& Rollnick, 2013). According to Geddis (1993), a teacher requires a multitude of components of such knowledge about a topic that is relevant to its teachability. However, the conceptual framework uses five components of the relevant knowledge, identified by Rollnick et al., (2008) and Mavhunga and Rollnick (2013), needed to pedagogically transform CK. These components are; the identification of key ideas and understanding of how they link to one another within a topic in a way that facilities learners understanding of the topic (curriculum Saliency), knowledge of what makes the topic difficulty or easy to teach and understand, learners 'prior knowledge, misconception and learning difficulties, presentations and analogies, and conceptual strategies. These knowledge components of TSPCK is from which the transformation of topic-specific CK emerges.

\section{Methodology}

\subsection{Research Design}

Assessing and capturing of PCK possessed by teachers could be very demanding, difficult and complex. Many scholars (Van Driel \& Berry, 2010; Guess-Newsome, 1999; Loughran et al, 2001, 2004) have pointed out that researchers often fail to acknowledge the complex relationships and interactions existing within PCK. This is partly because researchers are preoccupied with the development of instruments and procedures to make teachers' knowledge explicit and measure PCK in a valid manner overlooking that PCK can be sensitive to personal characteristics of teachers and their working context (Van Driel \& Berry, 2010; Guess-Newsome, 1999; Loughran et al, 2001, 2004). Thus PCK can be viewed at two levels; one as the theoretical knowledge possessed by a teacher and secondly, as the knowledge exhibited by the teachers' orientations, decisions and actions in class when teaching a topic. The former is more difficult to assess than the latter, and the two might be at variances because of other external factors that may influence teachers' orientations, decisions and actions in class. Moreover, a teacher may not be willing to share the knowledge or may decide not to be sincere for one reason or another. It is from this perspective that the study used descriptive research design within the pragmatist view which "recognizes that there are so many different ways of interpreting the world and undertaking research, that no single point of view can ever give the entire picture and that there may be multiple realities" (Saunders, Lewis \&Thornhill, 2012: 130). The triangulation technique was therefore critical in the collection, analysis and interpretation of data from the multiple sources

\subsection{Population and sample of the study}

The study population comprised of the grade 11 chemistry teachers in six selected secondary schools in Kitwe districts offering chemistry 5070 and science 5124. The overall sample size comprised of 35 chemistry teachers from the six schools.

\subsection{Research Instruments}

The study used the following data collection instruments; questionnaire, lesson observation, science topic PCK frameworks (CoRes and PaP-eRs), and focus group discussion. The study adopted the CoRes and PaP-eRs framework developed by Mulhall, Loughran and Berry (2003). The CoRes and PaP-eRs are valid and reliable frameworks for elucidating teachers PCK (Loughran, Berry \& Mulhall, 2006; Loughran, Mulhall \& Berry, 2004; Mavhunga \& Rollnick, 2013). The original framework had eight PCK probes, it was modified by splinting probe number eight 'What teaching strategies and particular reasons for using these strategies to engage learners with the idea?' into two separate probes 'what teaching strategies you use to teach this idea? and why do you use these strategies to engage learners with this idea? This modification brought the number of PCK probes to nine. The CoRes framework was used to capture both teachers' CK and PCK by responding to the nine probes on each of the underlying concepts for conceptual understanding of the mole concept. The CoRes probes for capturing each knowledge component of the mole concept PCK were as follows:

a) Curriculum saliency

1. What do you intend the learners to learn about this idea/concept 
2. Why is it important for learners to know this?

3. What else you might know about this idea that you don't intend learners to know yet?

b) What makes the topic difficult or easy to teach and understand

4. What difficulties and limitations connected with teaching this idea?

5. What do you know about your learners thinking that influences your teaching of this idea?

7. What other factors that influence your teaching of this idea?

c) Learners 'prior knowledge, misconception and learning difficulties,

5. What do you know about your learners thinking that influences your teaching of this idea?

6. What do know about learners' difficulties in learning this idea?

d) Presentations and analogies, and

8. What teaching strategies you use to teach this concept?

9. Why do you use these strategies to engage learners with the idea?

e) Conceptual strategies.

4. What difficulties and limitations connected with teaching this idea?

5. What do you know about learners' thinking that influences your teaching of this idea?

8. What teaching strategies you use to teach this concept?

9. Why do you use these strategies to engage learners with the idea?

The CoRes probes in practices are not explicitly and exclusively linked to the development of a specific TSPK knowledge component but they complement each other. They are vital tools that help teachers to identify and understand key aspects such as the underlying concepts, learners' preconceptions and ways framing ideas to support effective learning of the mole concept (Malcom, Mavhunga \& Rollnick, 2018; Mulhall, Loughran \& Berry 2003).

\subsection{Sampling and data collection}

The study used a non-probability multi-stage sampling process determined by the data collection technique, convenience and availability of participants. This was because the research process was emergent, naturalistic and interactive in nature (Ary, Jacobs \& Sorensen, 2010; Saunders, Lewis \& Thornhill, 2012). The 6 schools were purposely sampled because they offered both science 5124 and chemistry 5070 syllabi. All the 35 chemistry teachers in these schools were compressively sampled to answer the questionnaires out of which 30 complete the questionnaire. The questionnaire provided the baseline results for identification of the main aspects to focus on during lesson observations and focus group discussion. Using teaching time tables and schemes of work 5 grade 11 chemistry teachers were conveniently sampled for a series of lesson observations. After the lesson observations, all the five teachers whose lessons were observed, plus two teachers whose lesson were not observed were invited to complete the CoRes framework individually, bringing the total number of seven (7) participants. After that teachers were engaged into the focus group discussions guided by the completed CoRes so to capture their common mole concept Content Representation (CoRes) and gain access in their Professional-experience Repertoires (PaPeRs) in the teaching of the mole concept. All the lessons and the focused group discussion were video recorded.

\subsection{Data Analysis}

The analysis process involved the process of categorisation and cross-referencing of data from multiple sources of data. Some of the analytical frameworks that guided the analysis of qualitative data were the modified Fang, Hart and Clarke (2014) concept map for conceptual understanding of the mole concept, the three models for teaching amount of substance by Pakdag and Azizoglu (2013) and the CoRes by Mulhall, Loughran and Berry (2003). Apart from being used as the data collection instrument, the CoRes framework was used as the analytical tool in the analysis of the five knowledge components of the mole concept PCK. The CoRes has also embedded characteristics for capturing of the teachers' conceptual understanding of the mole concept.

\section{Results and Discussion}

The captured teachers' mole concept PCK is presented and discussed under the five knowledge components of TSPCK captured by the conceptual framework of the study.

\subsection{Curriculum saliency}

The discussion of the teachers' mole concept CoRes and how teachers presented the concepts under the mole concept topic indicated that teachers struggled to identify key ideas and understand how the ideas linked to each other within a topic in a way that facilities learners understanding of the mole concept. Their sequencing of the ideas within the topic and mole concept topic within the schemes of work was mostly influenced by the way textbooks and syllabi outlined the ideas and topics. Teachers taught the mole concept in the second term of grade 11 , as outlined by the syllabus, long after the following key and pre-request topics; atomic theory, periodic table and the language of chemistry had already been covered in grade 10 . To justify this sequence, teachers said that ... 
mole concept is taught in grade 11 because learners in grade 10 find it difficult to handle the mathematics involved under the topic. This cannot be considered as valid knowledge under this component of TSPCK. This is because the mathematics involved in the calculation of moles, concentrations, empirical formula, volumes mass of substances is simple arithmetic that is used in everyday life. This mathematics had already been taught way back in grades 7,8 and 9. Thus the study did not consider this as a valid justification for misplacing the mole concept in the teaching sequence of topics in chemistry. The challenge is not the mathematics but the lack of conceptual understanding of concepts and the meaning of the formulae presented to learners. It has already been discussed and reported in literature that teachers themselves struggle to teach the mole concept. This does not mean that teachers mathematics background is weak. Even if the topic is taught at grade 11 or any higher level, where learner's mathematical abilities are so high, studies have shown that learners still find mole concept to be a very difficult topic (Furio' et al., 2000; Furio, Azcon \& Guisasola, 2002). It was also observed that teachers introduced empirical formula before teaching the mole concept. This indicated that the participants did not adequately understand the meaning of the empirical formula and how the mole concept is linked to the meaning of the empirical formula. This limited their ability to effectively communicate the significance of the mole concept in the understanding of the quantitative aspect of chemical formulae, at the symbolic level.

The lesson observations and focus group discussion showed that teachers failed to explain the meaning of relative atomic mass and how it links the atomic theory and the mole concept. How the Observed teacher number one (OT1) presented the concept in class is a typical example of how participants taught relative atomic mass. OT1... Before we start the mole concept I would like us to look at relative atomic mass. Remember we defined relative atomic mass in grade $10 \ldots$ What is the relative atomic mass class? The class was quiet and the teachers continued... you have forgotten; you should be paying attention to definitions or else you won't remember the definitions during the examinations... relative atomic mass is the mass of an atom of an element compared to onetwelfth the mass of carbon-12 atom. You see carbon has been picked as the standard to which masses of atoms are compared to ok! The teacher went on to introduce the mole concept after that, without linking relative atomic mass to the mole concept. Teachers failed to show the link between relative atomic mass and molar mass. Scholars (Fang, Hart \& Clarke 2014; Malcolm, Mavhunga \& Rollnick 2018) have identified that the failure by a teacher to understand relative atomic mass and how it is linked to mole concept through the molar mass is of the underlying sources of teaching difficulties of the concept. It was also observed that when teaching the association among mass, molar mass and the amount of substance teachers explained to learners that... when calculating moles in given mass we either divide relative atomic/molecular or molar mass in a given mass of a sample. They called relative atomic mass or molar mass as mister abbreviated as Mr. This showed that teachers treated these concepts as one and the same, which indicated that they lacked the conceptual understanding of these two concepts. They did not adequately understand the difference between these concepts and how they are linked to each other.

Lack of conceptual understanding of underlying concepts under the mole concept topic limited the teacher's ability to decide which ideas and concepts within the topic were most central and which are more peripheral. It affected their planning, decisions and creativity in the teaching of the mole concept. These resonate with the findings of various studies in literature (Childs \& McNichol, 2007; Mavhunga \& Ronick, 2013; Sanders, Borko \& Lockard, 1993), which have shown that teachers 'planning, actions, decision making and creativity are very much affected by their CK. Further Sibanda (2018) points out that how teachers sequence the topics within the teaching scheme and ideas within the topic gives an insight into the teachers PCK. Thus the participants teaching sequence indicated that their mole concept PCK was inadequate.

\subsection{Knowledge of what makes the mole concept topic difficult or easy to teach and understand}

The findings showed that teachers had knowledge of why the mole concept was a difficult topic to teach. On the other hand, they did not exhibit in practice the ability to identify gate-keeping concepts, within the mole concept topic, that are difficult to understand. They did not show that dedicated awareness by coming up with possible interventions for teaching bridging concepts under the mole concept.

During the focus group discussion teachers identified the following as some of the factors that make the mole concept topic difficult to teach; the concept is abstract, learners find it difficult to understand new concepts under the topic, learners' poor mathematics background, and learners' perception that the mole concept is a very difficult topic. Most of these factors are learner related as opposed to the nature of the mole concept knowledge and didactic factors. This indicated that teachers did not consider their conceptual understanding and how they presented the ideas under the mole as some of the key factors that made the topic difficult to teach and understand. The observations showed that participants never made any effort to use methods that could have provided learners with an opportunity to link and understand the association among the abstract (microscopic), concrete (macroscopic) and representation (symbolic) concepts (Padilla et al.,2008). Understanding of the multiple meanings of the association embedded in conceptual network of the mole concept is key for teaching and learning the topic conceptually (Malcolm, Mavhunga \& Rollnick, 2018). The presentations of the associations among the amount of substance $(\mathrm{n})$, mass $(\mathrm{m})$, volume $(\mathrm{v})$ of gases at room or standard temperature and pressure and number 
of elementary particles $\left(\mathrm{N}_{\mathrm{A}}\right)$ were characterised by semantic mistakes and didactic challenges, echoing the findings by Pakdag and Azizoglu (2013). If teachers had strong mole concept PCK they would have used conceptual strategies that would have integrated the macro, micro and symbolic representation to differentiate the amount of substance, from mass and volume and to present the association among these concepts (Malcolm, Mavhunga \& Rollnick, 2018).

Learners' difficulties to understand new concepts and their perception of the mole concept as being difficult cannot be considered as valid knowledge under this component of TSPCK. This is because learners are bound to find any new concept in science difficult to understand. It is the role of a teacher through experience to identify what makes the concept difficult and come up with ways of presenting it in the form that could easily be understood by learners. Further, it has already been argued, contrary to the findings of other studies, that learners' poor mathematics background cannot be treated as the primary underlying source of teaching and learning difficulty of the mole concept. To start with mathematics is a tool used in science. Learners can only apply mathematical rules and operations appropriately to solve a scientific problem if they have a conceptual understanding of the concepts, laws, principles and theories that explain or govern a given scientific problem.

The challenge was that participants themselves did not adequately understand concepts under the mole concept. Their understanding of concepts like mass number, relative atomic mass, molar mass and actual mass of microscopic particles were characterised by serious misconceptions and wrong association of concepts at different knowledge levels. Their misconceptions and wrong association were exhibited when they were asked to state the actual mass of an oxygen $(\mathrm{O})$ atom during the focus group discussion. Teachers responded that... the actual mass of one oxygen $(O)$ atom is $16.00 \mathrm{~g}$. This was wrong, how can a microscopic particle weigh that much? The challenge here was not that participants didn't know how to use the four mathematical operations, but they did not have the conceptual understanding of relative atomic mass and molar mass. They did not understand that relative atomic mass is a convenient way of presenting the masses of microscopic particles using the atomic mass unit scale based on the one-twelfth the mass carbon -12 atom. The relative atomic mass of $\mathrm{O}$ atom (16.00) is not the actual mass of $\mathrm{O}$ atom, but the ratio of the actual average mass of $\mathrm{O}$ isotopes to the one-twelfth the actual mass of carbon- 12 isotope. While $16.00 \mathrm{~g}$ is the mass of $6.022 \times 10^{23} \mathrm{O}$ atoms called molar mass, the mass of one mole of a substance measured in grams per mole $(\mathrm{g} / \mathrm{mol})$. This quantity can be measured at the macroscopic level. This misconception was a limitation in understanding and teaching of the mole concept, and was one of the sources of a wrong association of knowledge levels and didactic challenges identified by Pakdag and Azizoglu (2013) in the teaching of the mole concept.

This shows that it was difficult for teachers without an adequate understanding of the concepts to reflect and identify what actually made the mole concept difficult to teach and understand. The fact that teachers could not examine and reflect on their conceptual and didactic limitations as some of the aspects that made the teaching of the mole concepts topic difficult to teach and understand, was an indication that even their mole concept Professional-experience Repertoires (PaP-eRs) was weak. These limitations pointed to the need to develop a Content Representations framework that may enhance both teachers' CK and PCK.

\subsection{Learners 'prior knowledge, misconception and learning difficulties}

The study found out that teachers struggled to identify learners' misconceptions and learning difficulties. They were not even aware that learners conceptual profile zone in understanding most of the ideas under the mole concept was within the common sense zone and not in the scientific domain. Learners viewed microscopic particles, atoms, ions and molecules (formula units) as tiny pieces of macroscopic world (elements and compounds). Thus they attributed properties, like mass in grams, belonging to macroscopic level to these particles echoing the findings by Pakdag and Azizoglu (2013). Learners associated the relative atomic masses of elements in the periodic table to the actual masses of atoms in grams. Teachers could not pick that as a misconception and at the same time a wrong association of knowledge levels macro, micro and symbolic. And learners associated the mole to mass.

Teachers found it difficult to deal with learners' wrong associations, conception and learning difficulties. This was because, to a larger extent, teachers were responsible for those misconceptions and learning difficulties. Teachers had the same conceptual challenges in understanding most of the concepts and hence they transmitted them to learners. Teachers conceptual shortcomings limited their ability to identify learners' difficulties in understanding of key concepts. It also affected their creativity and innovativeness in addressing learners' misconceptions. This shows that without sound CK it is very difficult to identify learners' misconception and learning difficulties. That is why sound CK is a precursor for quality TSPCK (Gess-Newsome, 2015; Kind, 2009, Mavhunga \& Rollnick, 2013). A teacher with sound mole concept PCK is likely to have knowledge about; the types of difficulties that learners experience, typical paths that learners' transverse to achieve understanding and potential strategies for helping learners overcome learning obstacles of the concept (Schulman, 1987). This knowledge is critical for effective teaching and learning of the mole concepts. 


\subsection{Presentations and analogies}

Knowledge of various ways of presenting concepts, use of analogies and appropriate examples is key for effective teaching and learning of any topic. The results indicated that teachers did not have adequate knowledge of how to come up with specific ways of framing different bridging concepts and ideas to support effective teaching and learning of the mole concept. The lesson observations and discussions of teachers CoRes revealed that participants used question and answer, discussion and teacher exposition in presenting concepts. They presented all underlying mole concept ideas and concepts using the general approach. They started presenting by first defining the concepts, then presented the formula, if calculations were involved, gave an example which was worked out by the teacher with the involvement of the class. After that, the teacher gave the class exercise which was either solved individually or in groups. This is a general approach to the teaching of any idea. They did not demonstrate the awareness that mole concept underlying concepts and ideas have different meanings and fall in different knowledge levels; macro, micro and symbolic level. The awareness might have provoked them to come up with different and creative ways of presenting various concepts to facilitate learners understanding of the mole concept.

Teachers demonstrated to have the general pedagogy, however, it was very difficult for teachers with conceptual limitations to come up with different strategies of explaining, giving of examples, and using analogies to support effective teaching and learning of different ideas. Presentation of the mole concepts ideas requires the use hands-on activities and analogies that would help learners to have a conceptual understanding of the embedded multiple meanings of the associations of the amount of substance with other quantities (Malcom, Mavhunga \& Rollnick, 2018).

\subsection{Conceptual strategies}

The teachers' mole concept CoRes and actual lesson presentations showed that teachers failed to come up with conceptual strategies to engage learners in the learning process of various concepts. Conceptual strategies give the teacher an opportunity to confront learners' confusion and misconceptions, and in turn engage learners in the construction of meanings from experience (Schulman, 1987). According to Malcolm, Mavhunga and Rollnick (2018:4) " ... conceptual teaching strategies go beyond the use of just pedagogical strategies but are informed considerations of the conceptual architecture towards mediating learning in the topic." Teachers struggled to use the combination of conceptual principles and rules of a topic as tools to confront potential confusion and misconception to facilitate the learning of the mole concept.

The conceptual principles and rules governing the understanding of the mole concept topic requires that teachers understanding should be within formal rationalist conceptual profile zone. In this zone network aspects of macroscopic measurements, mass and volume, are linked to the counting of a certain number of intangible entities. According to Padilla et al., (2008) this zone sustains a coherent and balanced relationship among the macroscopic, microscopic and symbolic levels of explanation. And the zone represents the accepted model of the amount of substance. Teachers struggled to come up with conceptual strategies because they did not adequately acquire this accepted model of the mole concept. The accepted model is part of the conceptual framework of this study as the modified concept map by Fang, Hart and Clark (2014) for a conceptual understanding of the mole concept. The concept map shows how the mole concept links to the atomic theory and multiple meanings of the associations among the macroscopic, microscopic and symbolic knowledge levels embedded in the conceptual network of the mole concept. The concept map addresses the link between relative atomic mass and molar mass, the gap identified by Malcom, Mavhunga and Rollnick (2018) as the missing link in the teaching of the mole conceptually.

\subsection{Model of the mole concept Content Representations framework.}

The discussion of the findings indicates that teachers were not adequately equipped with the knowledge components of the mole concept PCK and this was largely due to their weak topic CK. Teachers did not have adequate conceptual understanding of most of the underlying concepts under the topic which limited their ability to transform the mole concept $\mathrm{CK}$ in the manner that could be understood by learners. The inability was evident in their planning, decisions and the manner in which they presented the mole concept. The study, therefore, developed a model of the mole concept Representations Framework to show how the identified conceptual and teaching limitations can be addressed so as to enhance teachers' mole concept CK and PCK. The CoRes developed in other topics have been found to be useful tools in the enhancement of teachers' CK and PCK (Mulhall, Berry \& Loughran, 2003).

The PCK probes of the CoRes framework guided the study in addressing the identified conceptual limitations and pedagogical challenges to develop the model of the mole concept CoRes framework to enhance teachers' CK and PCK. The modified concept map by Fang, Hart and Clark (2014) was used as a framework to explain the multiple meanings embedded in the conceptual network of the mole concept. The model below gives a diagrammatic representation of how the key knowledge components of CoRes framework of the mole concept link together in enhancing teaching and learning of the mole concept. 


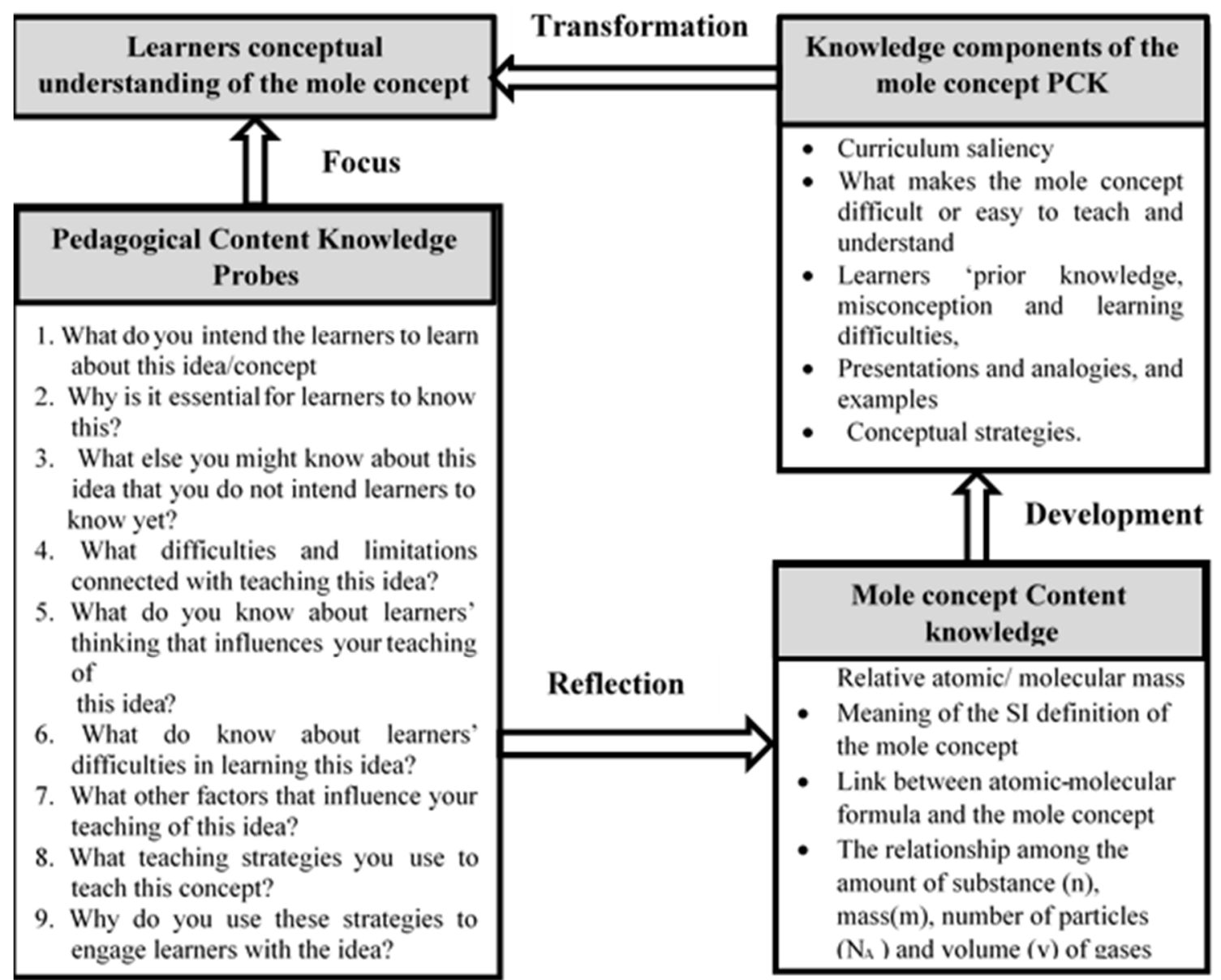

Figure 2. The Model of the Mole Concept Content Representations framework

The proposed model has 3 steps or phases that show how the model of the mole concept CoRes can enhance teachers' mole concept $\mathrm{CK}$ and their ability to transform content for learners understanding of the topic. The three steps are; reflection, development and transformation.

Reflection: At this stage, the PCK probes or questions about underlying ideas and concepts under the mole concept mole triggers the interaction and reflection among the following teachers' knowledge bases; content, pedagogy and the context. At the same time answering PCK probes directs the teachers' attention to focus on enhancing learners' understanding of the ideas and concepts.

Development: This stage could be considered to be a higher phase than the reflection level in the content presentation process. At this stage, the teacher has answered the nine PCK questions after the interaction and reflection process. Then the teacher goes further to develop the knowledge components, called the TSPCK, that is key for the transformation of the content.

Transformation: At this stage, the teacher uses the five knowledge components of TSPCK to transform the mole concept $\mathrm{CK}$ in the form that can easily be understood by learners. The teacher uses conceptual strategies that focus on different types of potential misconceptions and difficulties that learners experience in understanding ideas and concepts under the mole concept.

The study went further to answer the nine PCK questions in the above model on each underlying idea for conceptual understanding of the mole concept and come up with the detailed mole concept CoRes framework attached as an Appendix. The proposed mole CoRes framework has embedded features that simultaneously deals with mole concept CK and PCK in the presentation of each underlying concepts and ideas under the topic. The framework answers the PCK probes or questions that address most of the conceptual limitations and presentation challenges identified in the literature and in this study.

\section{Conclusion}

The study demonstrated that teaching difficulties and challenges of the mole concept stemmed from teachers' weak CK. Inadequate understanding of the underlying concepts and ideas under the mole concept hindered their development of adequate mole concept PCK knowledge components that are key in the presentation of the topic. It is against this backdrop that the study proposed the mole concept CoRes framework to enhance teachers CK and mole concept PCK as a way of improving learners understanding of the mole concept. Topic-specific CoRes 
frameworks have been proved to enhance the teachers' PCK and to promote effective teaching of topics in areas where they have been developed. The proposed mole concept CoRes framework provides a holistic approach to the enhancement of both teachers' CK and mole concept PCK. It blends content and pedagogy. Hence it provides a mechanism for the enhancement of both teachers' understanding and knowledge of conceptual strategies for effective teaching of the mole concept.

\section{Recommendations}

The findings brought out issues that may border on chemistry education programmes in teacher training and chemistry teachers' curriculum decisions as they teach the mole concept. Other issues may border on the gaps and weakness of the findings of the study that may be subject for further research. This because good studies should open more door for further studies for the advancement of knowledge and improved practice in education. The study made the following recommendations:

1. Chemistry education programmes should cover and integrate and blend content, pedagogy, and knowledge of other factors that influence the teaching of the mole concept in secondary schools. This might lay a very strong foundation for the development of PCK

2. Teachers should prepare the schemes of work in such a way that the mole concept is taught immediately after the atomic theory, the periodic table and the language of chemistry in grade 10. This will facilitate learners understanding of the link between atomic theory and the mole concept topic in chemistry, and appreciate the significance of the mole concept in chemistry.

3. Learners should be engaged in hands-on activities when learning the underlying concepts under the mole concept. Hands-on activities act as a window that provides learners with an opportunity to understand the associations among macro, micro and symbolic concepts within the multiple meanings embedded in the conceptual network of the mole concept.

4. The study recommends that further research is done to assess the effectiveness of the proposed framework and make recommendations for the advancement of knowledge and enhancement of teaching and learning of the mole concept topic.

\section{References}

Childs, A., \& McNicholl, J. (2007) Investigating the relationship between subject matter knowledge and pedagogical practice through the analysis of classroom discourse. International Journal of Science Education, 29 (13), 1629-1653

Fang, S.-C., Hart, C., \& Clarke, D. (2014). Unpacking the Meaning of Mole Concept for Secondary School Teachers and Students. Journal of Chemical education. 91, 351-356'

Fang, S.-C., Hart, C., \& Clarke, D. (2016). Identifying the critical components for a conceptual understanding of the mole in secondary science classrooms. Journal of research in science teaching, 53(2), 181-214.

Furio, C., Azcon, R., Guisasola, J., \& Ratclife, M., (2000) Difficulties in teaching the concepts of 'amount of substance' and mole. International Journal of Science Education, 22(12), 1285- 1304

Furio, C., Azcon, R., \& Guisasola, J., (2002) The learning and Teaching of the concepts 'amount of substance and mole: A Review of the literature. Chemistry Education: Research and Practice in Europe, 3(3), 277-292

Geddis, A. (1993). Transforming subject matter knowledge: The role of pedagogical content knowledge in learning to reflect on teaching. International Journal of Science Education, 15, 673-683

Guess -Newsome, J. (1999b). Pedagogical content knowledge: An introduction and orientation. In J. Guess Newsome, and N.G. Lederman (Eds.), Explaining pedagogical content knowledge. Dordrecht: Kluwer Academic

Grossman, P. (1990). The making of a teacher: Teacher knowledge and teacher education. New York: Teachers college express.

Kind, V. (2009). Pedagogical content knowledge in science education: perspectives and potential for progress. Studies in Science Education, 45(2), 169-204.

Padilla, K., Furio, C. (2007). The Importance of History and Philosophy of Science in Correcting Distorted Views of "Amount of Substance" and "Mole Concept" in Chemistry Teaching. Science Education, 17,403-424.

Padilla, K., Ponce-de-León, A. M., Rembado, F. M., \& Garritz, A. (2008) Undergraduate Professors' Pedagogical Content Knowledge: The case of 'amount of substance', International Journal of Science Education, 30(10), 1389-1404, DOI: 10.1080/09500690802187033

Padilla, K., Ponce-de-León, A. M., Rembado, F. M., \& Garritz, A. (2008) Undergraduate Professors' Pedagogical Content Knowledge: The case of 'amount of substance', International Journal of Science Education, 30(10), 1389-1404, DOI: 10.1080/09500690802187033

Pekdag, B., \& Azizoglu, N. (2013). Semantic and didactic difficulties in teaching the "amount of substance" concept: a useful model. Chemistry Education Research and Practice. (14), 117-129

Magnusson, S., Krajcik, J., \& Borko, H. (1999). Nature, sources, and development of the pedagogical content 
knowledge for science teaching. In J. Gess-Newsome, \&N.G. Lederman(Eds.), Examining pedagogical content knowledge. Dordrecht: Kluwer.

Malcolm, S.A., Mavhunga, E. \& Rollnick, M. (2018). A lesson on teaching the mole concept conceptually: A learning study. In L. Webb (Ed), Book of Proceedings: 26th Conference of the Southern African Association for Research in Mathematics, Science and Technology Education, (134-149). University of Gaborone, Botswana: SAARMSTE

Mavhunga, E., \& Rollnick, M. (2013). Improving Pedagogical Content Knowledge of Chemical Equilibrium in Pre-service Teachers. African Journal of Research in Mathematics, Science and Technology Education, 17(12), 113-125. http://www.tandfonline. com/page/. 5/07/15

Mortimer, E.F. 1995. Conceptual change or conceptual profile change? Science and Education, 4: $267-285$.

Mulhall, P., Berry, A., \& Loughran, J.J. (2003). Frameworks for representing science teachers' Pedagogical Content Knowledge. Asia-Pacific Forum on Science Learning and Teaching.4 (2). http://www.ied.edu.hk/apfsit/v4-issue2/mulhall/index. 14/08/2014

Rollnick, M., Bennett, J., Rhemtula, M., Nadine, D. \& Ndlovu, T. (2008) The Place of Subject Matter Knowledge in Pedagogical Content Knowledge: A case study of South African Teachers Teaching Amount of Substance and Chemical equilibrium. International Journal of Science Education,30 (10), 1365-1387

Sanders, L.R., Borko, H., \& Lockard, J.D. (1993). Secondary science teachers' knowledge base when teaching science courses in and out of their area of certification, Journal of Research in Science Teaching, 30(7), 723736

Saunders, M., Lewis, P., and Thornhill, A. (2012). Research Methods for Business Students. Essex: Pearson Educational Limited

Shulman, L.S. (1986). Those who understand: Knowledge growth in teaching. Educational Researcher, 15(2), 414.

Shulman, L.S. (1987). Knowledge and teaching: Foundation of the new reform. Harvard Educational Review, $57(1), 1-22$

Sibanda, D. (2018). What Sequence do we Follow in Teaching Concepts in Chemistry? A Study of High School Physical Science Teachers' PCK. African Journal in Mathematics, Science and Technology Education, 22(2) 196-208

Van Driel, J.H, \& Berry, A. (2010). Pedagogical Content Knowledge. International Encyclopaedia of Education (Third Edition), 656-661 http://www.sciencedirect.com/science. 12/04/2016

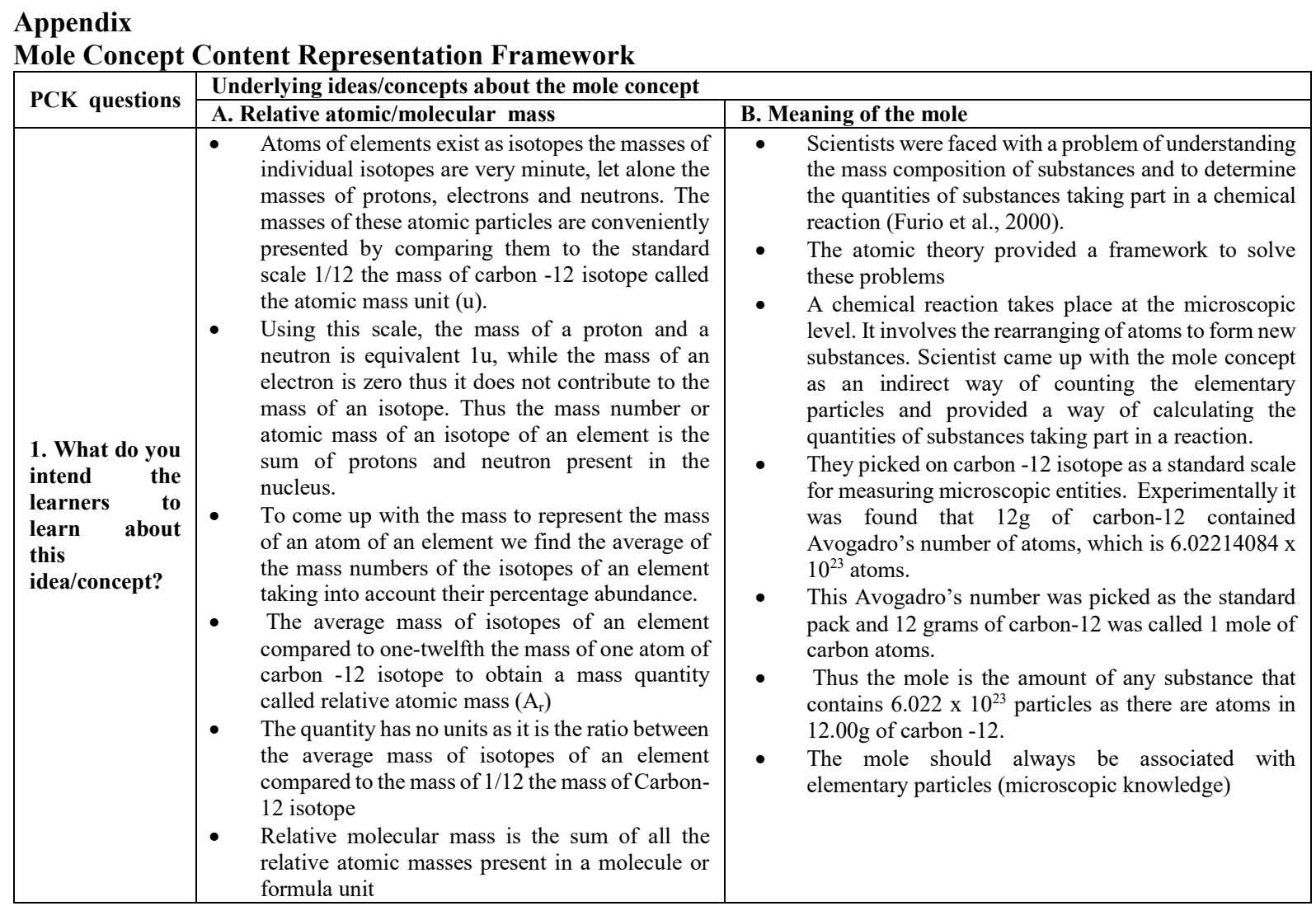


Vol.10, No.8, 2019

\begin{tabular}{|c|c|c|}
\hline \multirow{2}{*}{ PCK questions } & \multicolumn{2}{|l|}{ Underlying ideas/concepts about the mole concept } \\
\hline & \begin{tabular}{|l|l} 
A. Relative atomic/molecular mass & I
\end{tabular} & B. Meaning of the mole \\
\hline $\begin{array}{l}\text { 2. Why is it } \\
\text { important } \\
\text { for } \\
\text { learners to } \\
\text { know this? }\end{array}$ & $\begin{array}{l}\text { - Learners to know that masses of microscopic particles } \\
\text { are very minute, expressing and manipulating them } \\
\text { could be very difficult and cumbersome thus scientists } \\
\text { come up atomic mass unit scale, based on the } 1 / 12 \text { the } \\
\text { mass of carbon - } 12 \text { isotope, to measure or represent the } \\
\text { masses of microscopic particles (protons, neutrons, } \\
\text { atoms, molecules and formula units). } \\
\text { - Mass number represents the mass of isotopes of } \\
\text { elements in atomic mass unit NOT grams and it's a } \\
\text { whole number because it is the nucleon number. } \\
\text { - Relative atomic mass is the average mass of all the } \\
\text { isotopes of an element, expressed in atomic unit, } \\
\text { - Learners will understand that relative atomic mass is } \\
\text { not the actual mass of microscopic particles and it is } \\
\text { based on the atomic mass unit. }\end{array}$ & $\begin{array}{l}\text { - Understanding the historical perspective; why the } \\
\text { mole concept was introduced, the link between the } \\
\text { mole and the atomic theory the framework for the } \\
\text { understanding of chemical composition and reactions. } \\
\text { - Understand that the mole concept provided a way to } \\
\text { indirectly count the microscopic particles taking part } \\
\text { in a chemical reaction. } \\
\text { - This instils the appreciation of the significance of the } \\
\text { mole concept and where the concept sits. } \\
\text { - The description of the mole as a unit based on carbon } \\
\text { - } 12 \text { isotope provides a framework for understanding } \\
\text { that the amount of substance is a fundamental quantity } \\
\text { for measuring the microscopic particles and it } \\
\text { measured in moles. }\end{array}$ \\
\hline $\begin{array}{l}\text { 3. What else } \\
\text { you might } \\
\text { know } \\
\text { about this } \\
\text { idea that } \\
\text { you don't } \\
\text { intend } \\
\text { learners to } \\
\text { know yet? }\end{array}$ & $\begin{array}{l}\text { - The relationship between the atomic mass unit and the } \\
\text { gram scale using the one mole of carbon- } 12 \text { atoms to } \\
\text { explain the link between atomic theory and mole } \\
\text { concept through the mass. } \\
\text { - The measuring of relative atomic mass using the mass } \\
\text { spectrometer }\end{array}$ & $\begin{array}{l}\text { - The relationship between the atomic mass unit and } \\
\text { the gram scale in one mole of carbon atoms }\end{array}$ \\
\hline $\begin{array}{l}\text { 4. What } \\
\text { difficulties } \\
\text { and } \\
\text { limitations } \\
\text { connected } \\
\text { with the } \\
\text { teaching of } \\
\text { this idea? }\end{array}$ & $\begin{array}{l}\text { - The atomic mass unit is abstract in nature as it deals } \\
\text { with the microscopic knowledge level, masses of } \\
\text { microscopic particles cannot be measured directly } \\
\text { at the microscopic level } \\
\text { These concepts and their properties are abstract and } \\
\text { are very difficult to observe. }\end{array}$ & $\begin{array}{l}\text { - The SI definition is abstract in nature as it deals } \\
\text { with microscopic concepts which cannot be } \\
\text { directly observed and counted } \\
\text { The definition contains a lot of concepts at micro, } \\
\text { macro and symbolic levels makes it difficult to } \\
\text { comprehend } \\
\text { The SI definition of the mole does not explicitly } \\
\text { define the quantity 'amount of substance'. }\end{array}$ \\
\hline $\begin{array}{l}\text { 5. What do you } \\
\text { know about } \\
\text { learners' } \\
\text { thinking that } \\
\text { influences your } \\
\text { teaching of this } \\
\text { idea? }\end{array}$ & $\begin{array}{l}\text { Learners see the microscopic world as a smaller } \\
\text { version of their own macroscopic experience, } \\
\text { learners might view atoms of elements as the tiny } \\
\text { pieces of elements. } \\
\text { They can, therefore, attribute properties belonging to } \\
\text { macroscopic level to microscopic structures. } \\
\text { Thus they might think the mass number and relative } \\
\text { atomic mass are masses of atoms in grams. }\end{array}$ & $\begin{array}{l}\text { - } \\
\text { topic } \\
\text { - } \quad \text { Learners may find it difficult to understand the } \\
\text { amount of } \\
\text { substance and they relate it to mass or volume } \\
\text { They understand that the mole is the quantity and } \\
\text { the mol, the abbreviation of mole, as the unit }\end{array}$ \\
\hline $\begin{array}{l}\text { 6. What do } \\
\text { know } \\
\text { about } \\
\text { learners } \\
\text { difficulties } \\
\text { in learning } \\
\text { this idea? }\end{array}$ & $\begin{array}{l}\text { Difficulties in differentiating the two mass scales; } \\
\text { atomic mass unit and a gram scale } \\
\text { They find it difficult to differentiate relative atomic } \\
\text { mass and the actual mass of an atom in grams } \\
\text { Learner find it difficult to distinguish the following } \\
\text { concepts mass number, relative atomic mass and } \\
\text { molar mass }\end{array}$ & $\begin{array}{l}\text { - The comparison between the particles of any other } \\
\text { substance and that of particles found in exactly } \\
12 \mathrm{~g} \text { of carbon }-12 \text { isotope, has been a challenge. } \\
\text { The understanding that amount of substance is a } \\
\text { quantity is a challenge, they associate it to } \\
\text { physical quantities, mass and volume } \\
\text { - Learners may find it difficult to understand the } \\
\text { meaning of the association among the } \\
\text { macroscopic, microscopic and symbolic } \\
\text { knowledge within the SI definition of the mole } \\
\text { concept }\end{array}$ \\
\hline $\begin{array}{l}\text { 7. What other } \\
\text { factors } \\
\text { that } \\
\text { influence } \\
\text { your } \\
\text { teaching } \\
\text { of this } \\
\text { idea? } \\
\end{array}$ & $\begin{array}{l}\text { - Learners knowledge on the atomic theory and the } \\
\text { language of chemistry }\end{array}$ & $\begin{array}{l}\text { Learners' inadequate knowledge of atomic } \\
\text { theory and the language of chemistry } \\
\text { Abstract nature of the mole concept }\end{array}$ \\
\hline
\end{tabular}


Vol.10, No.8, 2019

\begin{tabular}{|c|c|c|}
\hline \multirow{2}{*}{ PCK questions } & \multicolumn{2}{|l|}{ Underlying ideas/concepts about the mole concept } \\
\hline & \begin{tabular}{|l|l} 
A. Relative atomic/molecular mass & B \\
\end{tabular} & Meaning of the mole \\
\hline $\begin{array}{l}\text { What } \\
\text { teaching } \\
\text { strategies } \\
\text { you use to } \\
\text { teach this } \\
\text { concept? }\end{array}$ & $\begin{array}{l}\text { - Explain how minute and how difficult it could be to } \\
\text { handle the masses of atoms in chemistry, illustrate this } \\
\text { by using the mass of carbon }-12 \text { isotopes: } 1.993355482 \\
\times 10^{-23} \mathrm{~g} \\
\text { - State the masses of atomic particles: proton }=1.6726 \times \\
10^{-24} \mathrm{~g}, \mathrm{Neutron}=1.6750 \times 10^{-24} \mathrm{~g} \text { and electron }=9 \text {. } \\
1095 \times 10^{-28} \mathrm{~g} \\
\text { - Work out the atomic mass unit }(\mathrm{u}) \text { the } 1 / 12 \text { the mass of } \\
\text { carbon }-12 \text { isotope } 1 / 12 \times 1.993355482 \times 10^{-23} \mathrm{~g}= \\
1.66 \times 10^{-24} \mathrm{~g} \\
\text { Express the masses of atomic particles in the atomic } \\
\text { mass unit by dividing their masses by } 1.66 \times 10^{-24} \mathrm{~g} \\
\text { Explain that the mass of an electron is negligible, only } \\
\text { neutrons and proton contribute to mass number, } \\
\text { define the mass number as the sum of protons and } \\
\text { neutron in the nucleus of an isotope of an element. } \\
\text { Carbon }-12 \text { isotope has } 6 \text { neutrons and } 6 \text { protons its } \\
\text { mass number or atomic mass is } 6+6=12 \text {. carbon }-14 \\
1 \text { sotope has } 6 \text { p and } 8 \text { neutrons it is the mass number is } \\
6+8=14 \text {. } \\
\text { These isotopes exist we need to find the mass that } \\
\text { represents them as the mass of carbon atom by finding } \\
\text { the average of their masses taking into account their } \\
\text { percentage abundance } \\
\text { Then define relative atomic mass the average mass of } \\
\text { isotopes of an element compared to one-twelfth the } \\
\text { mass of one atom of carbon }-12 \text {. } \\
\text { Explain that this holds for other elements because } \\
\text { their mass number that contributes to the average } \\
\text { mass is based on carbon }-12 \text { scale }\end{array}$ & $\begin{array}{l}\text { - Revise the atomic theory as a framework that } \\
\text { explains how substances react. And the challenges } \\
\text { associated with counting the trillions of these } \\
\text { microscopic particles of substances in a chemical } \\
\text { reaction, briefly discuss this within the historical } \\
\text { perspectives } \\
\text { Explain that most of the times in life we find it } \\
\text { convenient to count or buy and sell things in packs } \\
\text { of things, some of the packs are: A unit of eggs to } \\
\text { ten means } 10 \text { eggs; A dozen of books means } 12 \\
\text { books } \\
\text { Help learners understand that these packs are } \\
\text { about the numbers not any attributes of items in } \\
\text { those packs, the items or objects are at the } \\
\text { macroscopic level they can be counted directly. } \\
\text { Elementally particles are at the microscopic level, } \\
\text { can only be counted indirectly. } \\
\text { Scientist found that } 12 \mathrm{~g} \text { of C-12 isotope contained } \\
6.02214084 \mathrm{x} 10^{23} \text { atoms. This pack of particles } \\
\text { was called a mole (mol) and was picked as a } \\
\text { counting unit of elementally particles. } 12.00 \mathrm{~g} \text { of } \\
\text { C-12 became the mass of one mole of C-12 atoms } \\
\text { and was called molar mass. } \\
\text { The quantity for finding the standard packs in any } \\
\text { substance was called the amount of substance. } \\
\text { This quantity is about the number of elementary } \\
\text { particles in the standard pack (mole) and it was } \\
\text { defined as the amount of substance that contains } \\
6.022 \mathrm{x} 10^{23} \text { particles as there are atoms in } 12.00 \mathrm{~g} \\
\text { of carbon - } 12 \text {. } \\
\text { Make leaners understand the number } 6.02214084 \\
\mathrm{x} 10^{23} \text { is called Avogadro's number not that he is } \\
\text { the one who introduced the mole but honoured for } \\
\text { his hypothesis that equal volumes of gases contain } \\
\text { the same number of molecules provided they are } \\
\text { the same temperature and pressure. }\end{array}$ \\
\hline $\begin{array}{l}\text { 9. Why do you } \\
\text { use these } \\
\text { strategies } \\
\text { to engage } \\
\text { learners } \\
\text { with the } \\
\text { idea? }\end{array}$ & $\begin{array}{l}\text { - The above strategy will provide learners with } \\
\text { conceptual paths to effectively understand the } \\
\text { meaning, the link and the difference between mass } \\
\text { number and relative atomic mass. } \\
\text { It will also enable learners to understand the atomic } \\
\text { mass unit. }\end{array}$ & $\begin{array}{l}\text { This provides the learners with a historical } \\
\text { perspective of the mole concepts and the } \\
\text { significance of the concept in chemistry } \\
\text { It will enable learners to understand the multiple } \\
\text { meanings of the association of macro, micro and } \\
\text { symbolic concepts in the SI definition. } \\
\text { It will enable learners to understand that quantity } \\
\text { amount of substance is about counting the } \\
\text { microscopic particles, it is measured using the } \\
\text { standard park called the mole }\end{array}$ \\
\hline
\end{tabular}

\begin{tabular}{|c|c|c|}
\hline & $\begin{array}{l}\text { C. The link between atomic-molecular theory and the } \\
\text { mole concept }\end{array}$ & $\begin{array}{l}\text { D. The relationship among the mole }(n) \text {, mass }(m) \text {, } \\
\text { number of particles }\left(N_{A}\right) \text { and Volume }(V) \text { of gases }\end{array}$ \\
\hline $\begin{array}{l}\text { 1. What do you } \\
\text { intend the } \\
\text { learners to } \\
\text { learn about } \\
\text { this } \\
\text { idea/concept? }\end{array}$ & $\begin{array}{l}\text { - } 1 \text { mole of carbon contains } 6.02214084 \times 10^{23} \text { atoms } \\
\text { and each atom has } 12 \text { atomic mass units }(\mathrm{u})=1 / 12 \\
\text { the mass of } \mathrm{C}-12 \text { atom }=1.66053886 \times 10^{-24} \mathrm{~g} \\
\text { - } \\
6.02 \times 10^{23} \text { ato } \mathrm{s} \times\left(\frac{12 \times 1.66053886 \times 10^{-24} \mathrm{~g}}{\text { ato }}\right)=11.995 \approx 1 \mathrm{~m} \\
\text { (Zumdah, 2010) } \\
\text { This means that in } 1 \mathrm{~mole} \text { of a carbon-12 atom, a mole } \\
\text { of } 1 \mathrm{u} \text { is equal } 1 \mathrm{~g} \\
6.02 \times 10^{23} \text { atoms } \times 1.66053886 \times 10^{-24} \mathrm{~g} / \mathrm{atom}=1 \mathrm{~g} \\
\quad 6.02 \times 10^{23} \times 1.66053886 \times 10^{-24} \mathrm{~g}=1 \mathrm{~g} \\
\text { This relationship applies only to } 1 \mathrm{~mole} \text { of a } \\
\text { substance } \\
\text { The relative atomic mass of carbon element is } 12.01 \\
\text { (average of all mass numbers of carbon isotopes) thus } \\
\text { the mass of } 1 \mathrm{~mole} \text { of carbon atoms is given by } 12.01 \\
\times 1 \mathrm{~g}=12.01 \mathrm{~g} \text {. } \\
\text { 12.01g is NOT the mass of one carbon atom but the }\end{array}$ & $\begin{array}{l}\text { - Molar mass is the mass of one mole of any substance } \\
\text { thus it is measured in grams per mole }(\mathrm{g} / \mathrm{mol}) \\
\text { - For an element, the molar mass is the relative atomic } \\
\text { mass of the atom of that element expressed in } \mathrm{g} / \mathrm{mol} \\
\text { and this mass becomes the mass of } 6.02 \times 10^{23} \text { atoms } \\
\text { of that element. } \\
\text { - For molecules and compounds, their molar masses } \\
\text { are determined by expressing their relative } \\
\text { molecular/ formula unit masses in g/mol and this } \\
\text { becomes the mass of } 6.02 \times 10^{23} \text { molecules or } \\
\text { formula units of a compound or molecules of an } \\
\text { element. } \\
\text { - Given any mass of a substance (measured mass in } \\
\text { grams) to determine the number of moles present in } \\
\text { that mass we divide the mass per mole (molar mass) } \\
\text { into the mass. } \\
\text { number of moles (n) } \frac{\text { m ass }(\mathrm{g})}{\text { molar mas }(\mathrm{g} / \mathrm{mol})}=\text { mol } \\
\text { Molar volume }\left(\mathrm{dm}^{3} / \mathrm{mol}\right) \text { is the volume occupied by } \\
\text { any gas at r.t.p or s.t.p. Given any volume of a gas at } \\
\text { these conditions, the number of moles is determined }\end{array}$ \\
\hline
\end{tabular}




\section{The link between atomic-molecular theory and the} mole concept

mass of $6.02 \times 10^{23} \mathrm{C}$ atoms and is called mola mass is given in grams $/$ mole $(\mathrm{g} / \mathrm{mol})$

- Since carbon-12 isotope is the standard measure of relative atomic mass $\left(A_{r}\right)$ and the amount of substance(n), the above-explained link between relative atomic mass and the molar masses holds even for other elements (fang, Hart \& Clark, 2014). The relative atomic mass of $\mathrm{Cl}$ is 35.5 atomic mass units and the mass of one mole of $\mathrm{Cl}$ atoms is given by 35.5 $\times 1 \mathrm{~g}=35.5 \mathrm{~g}$

- The two are different quantities; Relative atomic mass is the ratio of the mass of one atom of an element to $1 / 12$ the mass of one atom of carbon- 12 while molar mass is the mass of one mole of elementary particles of a substance. Meaning the mass of $6.02 \times 10^{23}$ particles.
D. The relationship among the mole (n), mass (m), number of particles $\left(\mathrm{N}_{\mathrm{A}}\right)$ and Volume $(\mathrm{V})$ of gases

by dividing the volume occupied by one mole of gas (molar volume) in a given volume

$$
\text { number of moles }(\mathrm{n})=\frac{\text { volume }\left(\mathrm{dm}^{3}\right)}{\mathrm{molarvolume}\left(\mathrm{dm}^{3} / \mathrm{mol}\right)}=\mathrm{mol}
$$

- One mole of any substance contains $6.02 \times 10^{23}$ particles. We can, therefore, count the number of elementally particles indirectly in a measured mass in grams and volume of gases at r.t.p and s.t,p in $\mathrm{dm}^{3}$ by first finding the number of moles. Then multiply the moles by the number of particles per mole $\left(\mathrm{N}_{\mathrm{A}}\right)$ $\left(6.02 \times 10^{23}\right.$ particles $\left./ \mathrm{mole}\right)$

$\mathrm{N}_{\mathrm{A}}=$ mole $\times 6.02 \times 10^{23}$ particles $/ \mathrm{mol}=$ particles.

- $\quad$ To understand that relative atomic mass and molar mass are different quantities in terms of

\begin{tabular}{c|l} 
2. Why is it & the scale and what they represent \\
important & - The above understanding helps the learners not
\end{tabular} $\begin{array}{lll}\text { important } & \bullet & \text { The above understanding helps the learners not } \\ \text { for learners } & & \text { to confuse relative atomic/molecular mass and }\end{array}$ to know molar mass

this?

- Understand how the atomic-molecular theory links to the mole concept through relative atomic mass and molar mass

3. What else you might know about this idea that you

- How the relative atomic masses of elements are don't intend learners to know yet?

- Learners to have a conceptual understanding of the meanings of association among the amount of substance(n), mass (m), volume(V) and the number of particles $\left(\mathrm{N}_{\mathrm{A}}\right)$.

determined using a mass spectrometer.
- The association between the moles of electrons and the mass of the substances deposited at the electrodes during electrolysis.
- Linking relative atomic/molecular mass to molar mass could a challenge,

\section{What}

difficulties

and

limitations

connected

with the

teaching of

this idea?
Making learners understand that, although they can observe elements and compounds at macroscopic level it is not possible to observe the elementary particles.

- Learner find difficulty to simultaneously understand the meanings of the associations among the amount of substance(n), mass(m), volume $(\mathrm{V})$ and number of particles $\left(\mathrm{N}_{\mathrm{A}}\right)$, because these quantities are at different levels of chemistry knowledge (macro, micro and representational)

- Learners find difficult to link masses of gases measured at r.t,p and s.t.p to volume, moles and number of particles

- Learners are attempted to think that the $6.02 \mathrm{x}$ $10^{23}$ particles contained in one mole of a substance are tiny versions of pieces of elements and compounds.

- $\quad$ Hence they may attribute the physical characteristics belonging to elements and compounds to elementary particles

- Understanding the difference between relative atomic molecular mass and molar mass.

- How to form correct associations among the macro, micro and symbolic knowledge levels.

- Learners may face difficulties to find the volume by a given mass of a gas understand how relative atomic/molecular mass is linked to the mass of one mole of these microscopic particles.

learners difficulties in learning

- Hence finding it difficult to understand that this idea? microscopic particles can be counted indirectly using the relationships between mass and molar mass

7. What other

factors that

influence

- Understanding of the atomic-molecular your teaching of

\section{theory}

- learners thinking and misconceptions
Multistage reasoning in problems involving may pause a challenge to Learners

- Learners perceive the mole concept to be a difficult topic 
Vol.10, No.8, 2019

\begin{tabular}{|c|c|c|}
\hline & $\begin{array}{l}\text { C. The link between atomic-molecular theory and the } \\
\text { mole concept }\end{array}$ & $\begin{array}{l}\text { D. The relationship among the mole }(n) \text {, mass }(m) \text {, } \\
\text { number of particles }\left(N_{A}\right) \text { and Volume }(V) \text { of gases }\end{array}$ \\
\hline this idea? & & - $\quad$ Lack of chemicals, apparatus and equipment \\
\hline \multirow[t]{2}{*}{$\begin{array}{l}\text { 8. What teaching } \\
\text { strategies } \\
\text { you use to } \\
\text { teach this } \\
\text { concept? }\end{array}$} & 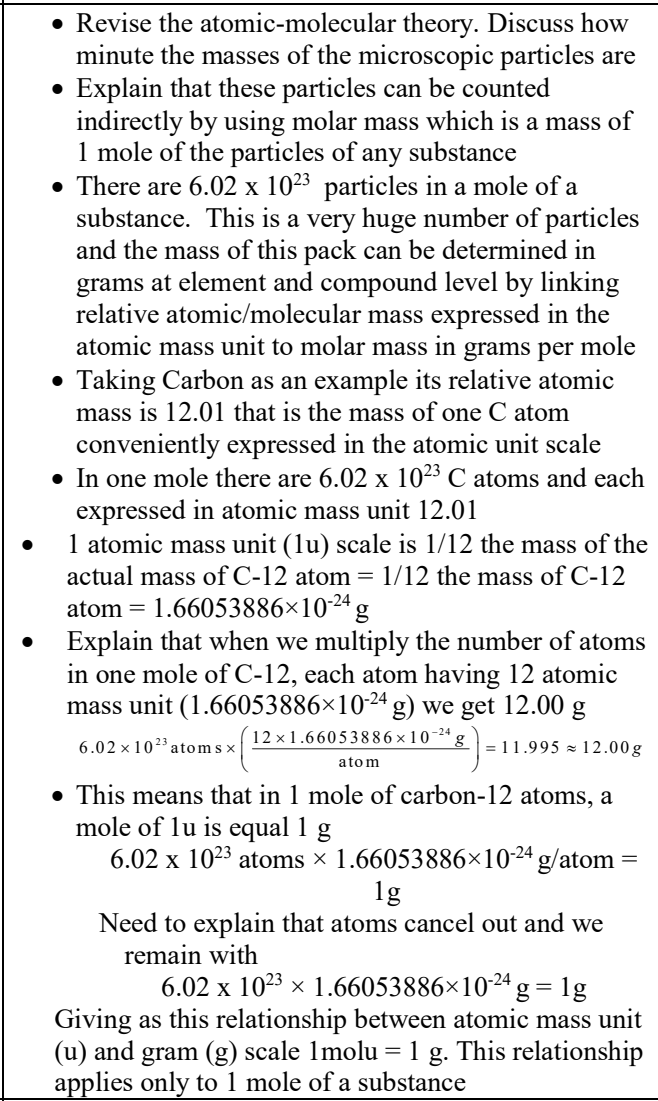 & $\begin{array}{l}\text { - Show the learners different elements and } \\
\text { compounds let say copper }(\mathrm{Cu}) \text { and sodium } \\
\text { chloride }(\mathrm{NaCl}) \text { and ask learners to state their } \\
\text { relative atomic and relative molecular masses } \\
\text { Explain that } 63.55 \text { the relative atomic mass for } \\
\text { copper }(\mathrm{Cu}) \text { is the convenient way of representing } \\
\text { the masses of an individual } \mathrm{Cu} \text { atom, and } 58.44 \\
\text { the relative molecule mass represents the mass of } \\
\text { a formula unit of } \mathrm{NaCl} \text { compared to one-twelfth } \\
\text { the mass of Carbon-12 isotope. } \\
\text { Give learners an activity to measure } 63.55 \mathrm{~g} \text { of } \mathrm{Cu} \\
\text { and } 58.44 \mathrm{~g} \text { of NaCl and explain that } 63.55 \mathrm{~g} \text { is the } \\
\text { mass of } 6.02 \mathrm{x} 10^{23} \text { (one mole) of Cu atoms. } \\
58.55 \mathrm{~g} \text { is the mass of } 6.02 \mathrm{x} 10^{23} \text { (one mole) of } \\
\text { NaCl formula units. These particles cannot be } \\
\text { seen because they are at the microscopic level. } \\
\text { State that these masses are called molar masses; } \\
\text { the mass of one mole of any substances. } \\
\text { Theoretically, they are determined by expressing } \\
\text { the relative atomic/molecular mass of a substance } \\
\text { in grams per mole (g/mol) } \\
\text { Ask learners to measure any mass of Cu and } \mathrm{NaCl} \\
\text { and tell them to find the numbers of moles and the } \\
\text { number of particles in those masses since they } \\
\text { know the mass per mole of that substance } \\
\text { Guide them to represent their reasoning as follows } \\
\text { number of moles (n) }=\text { mass }(\mathrm{g} \text { ) } \\
\end{array}$ \\
\hline & $\begin{array}{l}\text { The relative atomic mass of carbon element is } 12.01 \text {, } \\
\text { using the above relationship, the mass of } 1 \mathrm{~mole} \text { of } \\
\text { carbon atoms is given by } 12.01 \times 1 \mathrm{~g}=12.01 \mathrm{~g} \text {. } \\
12.01 \mathrm{~g} \text { is the mass of } 6.02 \times 10^{23} \mathrm{C} \text { atoms and is } \\
\text { called molar mass given in grams per mole }(\mathrm{g} / \mathrm{mol}) \\
\text { Since carbon-12 isotope is the standard measure of } \\
\text { relative atomic mass (Ar) and the amount of } \\
\text { substance (n), the above-explained link between } \\
\text { relative atomic mass and the molar masses holds } \\
\text { even for other elements. The relative atomic mass of } \\
\text { Cl is } 35.5 \text { atomic mass units and the mass of one } \\
\text { mole of Cl atoms is given by: } 35.5 \times 1 \mathrm{~g}=35.5 \mathrm{~g} \\
\text { Explain that this why when determining theoretically } \\
\text { the molar mass of substance we start by determining } \\
\text { their relative atomic/molecular mass and then we } \\
\text { convert it to molar mass using the above relationship } \\
\text { that the two are different quantities. Relative atomic } \\
\text { mass is the ratio of the mass of one atom of an } \\
\text { element to } 1 / 12 \text { the mass of one atom of carbon- } 12 \\
\text { while molar mass is the mass of one mole of } \\
\text { elementary particles of a substance. Meaning the } \\
\text { mass of } 6.02 \times 10^{23} \text { particles. }\end{array}$ & 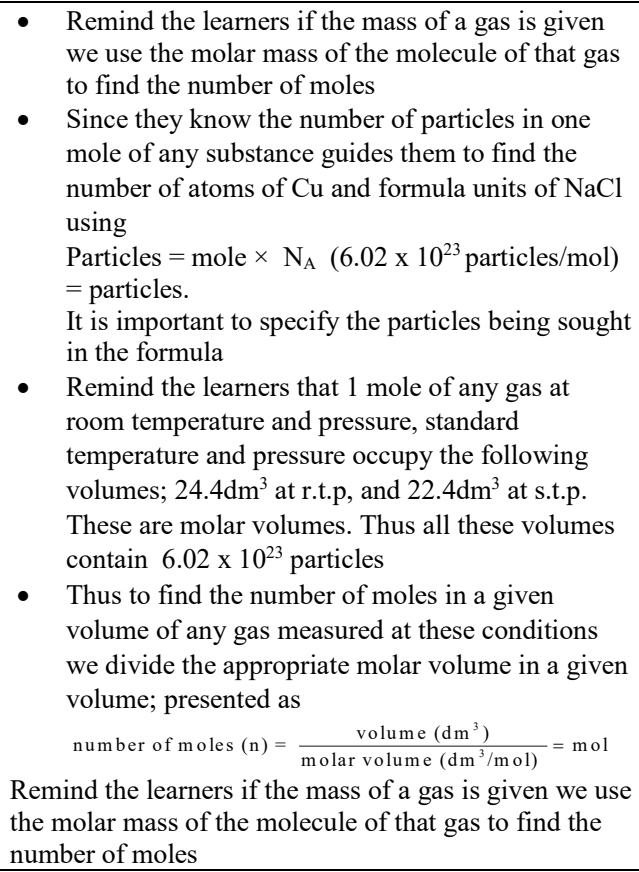 \\
\hline $\begin{array}{l}\text { 9. Why do you } \\
\text { use these } \\
\text { strategies to } \\
\text { engage } \\
\text { learners } \\
\text { with the } \\
\text { idea? }\end{array}$ & 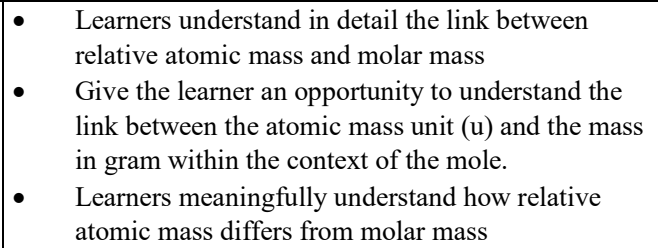 & $\begin{array}{l}\text { - The learning process is effective and meaningful. } \\
\text { It gives learners an opportunity to manipulate the } \\
\text { macroscopic concepts and explain them using } \\
\text { microscopic and symbolic concepts } \\
\text { It accords them an opportunity to take part in the } \\
\text { construction of the meaning of the concept. }\end{array}$ \\
\hline
\end{tabular}

